\title{
Influência das concepções europeias na formulação do pensamento urbanístico paulista
}

\author{
Rodrigo Alberto Toledo \\ Doutorando em Ciências Sociais (Universidade Estadual Paulista Júlio de Mesquita Filho)
}

ro-toledo@hotmail.com.br

\begin{abstract}
Resumo $O$ presente artigo pretende elencar as principais influências sofridas por arquitetos urbanistas na formulação de um pensamento urbanístico paulista. Desta forma, discutiremos as principais questões levantadas no período, desde as primeiras décadas do século XX até o fim da década de 1950, buscando antever como engenheiros e arquitetos trabalharam ao incorporar as propostas urbanísticas americana e europeia. Destarte, apresentaremos, nas três primeiras seções deste artigo, as concepções que efetivamente impactaram o pensamento urbano paulista da primeira metade do século XX: Sanitarismo, concepção pendular: entre a Teoria Mesológica e a Teoria Microbiana; A formulação historicista de Camillo Sitte; A cidade-jardim de Howard e a experiência francesa. Nossas análises foram elaboradas a partir de ampla sistematização bibliográfica e documental realizada no Arquivo Histórico Municipal (Intermediário) de Araraquara (SP), consultas ao acervo da biblioteca da Faculdade de Arquitetura e Urbanismo da USP e da Faculdade de Ciências e Letras da Unesp de Araraquara. As análises dos levantamentos sistematizados apontam que se efetivaram duas correntes urbanistas no estado de São Paulo, com nítidas influências das concepções que conduziram os debates dos urbanistas na primeira metade do século XX. Entretanto, essas concepções compõem um quadro de intervenções urbanas na cidade de São Paulo $\mathrm{e}$, visivelmente, em algumas cidades do interior paulista anteriores à solidificação de uma proposta interventora totalizante de cidade, denominada, posteriormente, de Plano Diretor.
\end{abstract}

Palavras-chave: pensamento urbano, planejamento urbano, democracia, participação, políticas públicas.

\section{Sanitarismo, concepção pendular: entre a teoria mesológica e a teoria microbiana}

$\mathrm{D}$ ESDE O SÉCulo XIX, ${ }^{1}$ as cidades, não só do Brasil, vinham sendo problematizadas em diversos aspectos. Os médicos exerceram papel importante nesse processo, por levantar uma de suas questões centrais: a higiene. Engenheiros sanitaristas do fim do século XIX apresentaram e concretizaram, de forma mais centrada e cabal, as questões e soluções que os médicos estavam elaborando desde o início desse século. Classificamos em três as principais questões urbanas elaboradas nesse período: a higiene, a circulação e a estética. O fator econômico perpassava todas elas. 
Para Damasceno (1996, p. 45), “os médicos propunham-se a dar respostas adequadas a uma das principais questões apresentadas pela sociedade: a saúde e a qualidade de vida dos centros urbanos, num momento em que o crescimento das cidades provocava a degradação das condições de vida". Segundo ainda Damasceno (1996), a medicina desse período não se restringia somente aos aspectos clínicos da saúde, mas também a um espaço social que deveria ser estudado junto com o espaço físico.

Era essa a perspectiva utilizada tanto por médicos quanto por reformadores do século XIX ao tentar entender os problemas da cidade, cujos males, para eles, estavam relacionados às emanações pútridas, os chamados miasmas, de matérias orgânicas em decomposição existentes em pântanos, águas estagnadas, esgotos, do ar viciado das habitações coletivas e da falta de circulação.

As epidemias que assolaram as cidades brasileiras a partir do século XIX impuseram mudanças em suas organizações. Paralelamente a elas, as mudanças sofridas pela sociedade brasileira, consubstanciadas na formação de um exército de mão de obra assalariada, levaram a uma crescente preocupação com a manutenção/sobrevivência do trabalhador livre, principalmente o estrangeiro, uma vez que as enfermidades colocavam em risco o fluxo migratório.

Para Fernandes (1995, p. 66),

grande parte do raciocínio que justificava a importância do saneamento das cidades se prendia precisamente ao cálculo econômico, sendo comum várias referências à economia realizadas pelo fato de se baixar em um ou dois pontos a taxa de mortalidade nas cidades, demonstrando cabalmente a necessidade econômica do higienismo.

O pano de fundo dessas questões havia sido um debate teórico-científico entre os higienistas no fim do século XIX. Um grupo adotava a teoria do sanitarismo mesológico, enquanto o outro adotava o microbiano. Vejamos a seguir.

Os problemas relativos à circulação e à estética podem ser analisados dentro da mesma concepção, ou seja, a circulação estava diretamente ligada ao escoamento da produção, assim como ao acesso dos trabalhadores a suas áreas de trabalho, estando, portanto, associada à mobilidade de capital.

Entendemos, contudo, que ocorre uma melhoria na infraestrutura de determinadas zonas da cidade, em detrimento de outras. Essa concepção dialoga diretamente com os planos de melhoramentos que determinaram as transformações pelas quais sofreram o centro das principais cidades brasileiras no início do século XX. Naquela época, o enfoque era a circulação de pessoas, mercadorias e fluidos.
A estética estava relacionada ao aspecto que se pretendia formar para essas cidades: civilizadas, higiênicas e modernas. Essas características poderiam possibilitar contatos financeiros efetivos com o capital internacional; dessa forma, em grande medida, o que estava em jogo era o imaginário de cidade que se pretendia "comercializar".

Essas cidades precisavam transformar-se em espaços atrativos para o capital internacional, pois o novo papel que o Brasil ocupava na divisão internacional do trabalho demandava uma visão mercadológica do espaço urbano.

Segundo Andrade (1992, p. 87 apud Costa, 2003, p. 5),

A cidade como manufatura desenvolveu-se como o avanço do processo de urbanização do capitalismo industrial [...]. Na virada do século XIX para o XX, com a cultura urbanística oscilando entre a cidade como obra de arte e a cidade como manufatura, determinações delimitavam campos do conhecimento e disciplinas distintas. Para alguns urbanistas de então, entre os quais Camillo Sitte, tratava-se de conciliar as dimensões técnica e estética na construção das cidades.

Esses capitais, segundo Szmencsány (1993), não apenas foram capazes de colaborar entre si, como também se mostraram aptos a obter o apoio do Estado na provisão de serviços públicos essenciais, na regulação do parcelamento das terras com venda de lotes e na criação de infraestrutura física dos sistemas de transporte e saneamento.

A cidade, portanto, era ela própria uma mercadoria. Esse aspecto é interessante, pois revela que a questão estética era extremamente forte, a exemplo das propostas urbanísticas elaboradas por Sitte e Haussmann. Já a vertente americana estava associada à questão do capital, da interação entre o público e o privado e da administração. São Paulo insere-se nessa dinâmica, sem, entretanto, negar a nítida influência europeia que sofreu, ou seja, incorpora parâmetros estéticos e higiênicos, mas também se volta para a questão do capital transformando seu espaço em área de expansão do capitalismo imobiliário especulativo.

O debate sobre higiene, circulação e estética do período pode ser entendido como um desmembramento dos questionamentos entre a função - papel que desempenhava a cidade em questão no contexto em que se inseria - e a forma, ou seja, seu desenho.

Não podemos esquecer que um dos instrumentos dessa época era a legislação. Os códigos de posturas e as leis higienistas decretadas no período apontam para isso. Paralelamente ao debate produzido sobre a necessidade de a população promover uma mudança de mentalidade, existia uma corrente que defendia que as mudanças de hábitos, dos costumes e das crenças 
vigentes no período só ocorreriam por meio de uma ação coercitiva da lei. Contudo, para além dessa constatação, esses instrumentos constituem os primeiros dispositivos de normalização da construção civil, e, de certa forma, são antecedentes dos atuais códigos de obras (códigos de posturas). O debate teórico-conceitual e prático revela as propostas do sanitarismo no fim do século XIX e início do século XX, ou seja, o pano de fundo desse debate é a questão do saneamento de cunho mesológico e de cunho microbiano.

Em Andrade (1992, p. 89), identificamos uma conceituação a respeito da teoria mesológica e da teoria do contágio, que busca explicar

as condições do meio que favoreciam as doenças, bem como o modo delas se propagarem. Assim, após a descrição da topografia sanitária das cidades assoladas pelo mal, segue-se o registro dos pontos de passagem ou estadia dos doentes, bem como a condenação de reuniões e cerimônias coletivas. Revela-se, assim, que o controle das epidemias passará por uma ciência do território, dependerá de uma política geopolítica e será exercido sobre grandes massas populacionais, anunciando modernas formas de controle político.

Os métodos utilizados para controle das epidemias contavam com a criação do cordão sanitário, a quarentena, as fumegações, as fogueiras aromáticas, as lavagens de cal branca e as rezas. Às vezes, quando a moléstia já estava instalada na cidade, a solução era abandoná-la. ${ }^{2}$

A engenharia sanitária do início do século XIX tinha como tarefa impedir o contágio em uma situação de amontoamento. Por assim ser, não será à toa a presença de higienistas e sanitaristas entre os principais formuladores das concepções organicistas da cidade, com frequentes analogias entre a saúde da cidade e a do corpo humano. As intervenções urbanas da engenharia sanitária estavam pautadas no objetivo último de fazer com que as águas circulassem de maneira salubre. Era preciso ordenar o seu fluxo e conduzi-las aos esgotos.

A teoria que mais se articulou no século XIX e que se constituiu como a mais legitimada e aceita no decorrer do século XX, no entanto, foi a microbiana. $\mathrm{O}$ que promoveu um intenso debate entre a teoria mesológica e a microbiana foi a constatação de Louis Pasteur de que os micróbios é que transmitiam as doenças, e não os miasmas, como era até então difundido e aceito.

Segundo Costa (2003, p. 90),

ao atribuir a fermentação a micro-organismos, Pasteur conseguiu, pela primeira vez na história da me- dicina, precisar a casa das doenças, assim como desenvolver mecanismos para evitar tais enfermidades: as vacinas. No Brasil, o principal seguidor dessa teoria foi Oswaldo Cruz. Foi sob sua administração que a Diretoria Geral de Saúde Pública, do governo de Rodrigues Alves (1902-1906), no Rio de Janeiro, protagonizou, segundo Sevcenko (1996), um dos episódios menos compreendidos da história recente do país: a Revolta da Vacina.

O tifo, a tuberculose, a lepra e a varíola assolavam o Rio de Janeiro e colocavam em risco a economia do país. Diante desse problema, Oswaldo Cruz recebeu plenos poderes do governo federal para sanear a cidade. $\mathrm{O}$ que foi feito com muita competência e organização, mas também com muito autoritarismo, introduzindo campanhas sanitárias de cunho nitidamente militar.

Os objetivos dos planejadores do fim do século XIX e início do século XX eram, segundo Campos (2002), “assegurar condições mínimas de vida para uma população em rápido crescimento, normalizar a ocupação e o uso dos espaços e equipamentos e adequar a cidade aos negócios, às instituições e ao poder burguês". Nesse sentido, a normalização da ocupação e do uso do solo era o aspecto mais importante dos planos realizados em São Paulo. Nessa perspectiva, a teoria mesológica ganhava outro sentido e mais adeptos, pois, no embate com a teoria microbiana, justificava cientificamente a dominação do espaço.

Por fim, depreendemos que não havia tanta diferença entre as medidas a serem tomadas e os resultados obtidos. Enquanto a teoria microbiana atacava as causas, a teoria dos meios atacava não a doença em si, mas as condições propícias à sua manifestação. Assim, para o planejamento urbano, não havia tanta diferença em ser seguidor de uma ou de outra teoria. Fato inconteste é que ambas contribuíram para a gênese de uma normalização da ocupação e do uso do solo urbano.

\section{A formulação historicista de Camillo Sitte}

O livro de Camillo de Sitte, $A$ Construção das cidades segundo seus princípios artísticos (1992), foi imediatamente recebido pelos profissionais da área. Segundo alguns autores, o livro era uma resposta crítica às obras que o Barão de Haussmann executou em Paris no século XIX e, em um patamar mais amplo, uma crítica à forma como as cidades vinham sendo erguidas naquela época. 
O livro utiliza um amplo aporte histórico como forma de compreensão dos princípios que guiaram, no passado, a construção das cidades e que deveriam ser apreendidos em sua essência. A análise histórica assume, para Sitte (1992), uma opção metodológica que revela uma essência estético-antropológica no construir as cidades, na qual as dimensões tácitas do espaço são determinantes para o sucesso da empreitada. O autor, logo na introdução de seu livro, evoca Aristóteles e Pausânias - para os quais não se pode chamar de cidade um lugar onde não existam praças e edifícios públicos - para defender que a construção da cidade deve ser pensada não apenas como uma questão técnica, mas, antes, estética. Conforme Sitte (1992), a arte poderia ceder lugar, quando fosse o caso, aos aspectos de higiene ou a outros que se apresentassem como prioritários, justificando sua pesquisa como forma de apresentação dos conhecimentos antigos no tratamento do espaço público.

As praças deveriam, segundo o autor, relacionar-se com as ruas e com as edificações, de maneira que as ruas ficassem perpendiculares à linha de visão. Sitte (1992) era contra espaços vazios, contrapondo-os aos espaços com a presença de edifícios e obras de arte que, dependendo da distribuição, poderiam causar sensação de fechamento, aconchego, o que ele identificava na cidade antiga e gostaria de conservar. Criticava as ruas retas, que só atenderiam à circulação, não dando a devida atenção ao fator estético. As alamedas e os jardins só encontram bons resultados nos bairros residenciais, segundo Sitte (1992). A área central da cidade mereceria especial atenção, pois a vegetação mal localizada atrapalha a apreciação das obras principais. Os jardins modernos, abertos, fogem aos objetivos da higiene a que se propõem, principalmente durante o verão, quando a livre circulação dos ventos espalha poeira e calor, e as novas avenidas e os novos requisitos da circulação e da economia são incompatíveis com as antigas características dos espaços públicos.

No fim de seu livro, Sitte (1992) apresenta uma sistematização das ideias anteriormente expostas, sugerindo um método projetual: primeiro, um estudo das condições de contorno e, em seguida, uma resposta a essas condições. Defende, então, a necessidade de um plano conjunto, o qual chama de programa a ser seguido, que constaria de dois pontos fundamentais: a) o estudo do possível crescimento da cidade (com um horizonte de 50 anos), denotando certa separação de funções (circulação, residência, vilas suburbanas e zonas destinadas a comércio e indústrias); b) "com base nessas informações indispensáveis, deveriam ser definidas a quantidade, as dimensões e a forma aproximada dos edifícios públicos programados" (Sitte, 1992, p. XX).

A contribuição de Sitte (1992) está na forma como propõe a elaboração de um estudo das cidades. Primei- ro, trabalha com uma projeção (50 anos) em que essas mudanças deveriam ocorrer; em segundo lugar, apresenta uma concepção de cidade que considera aspectos que influenciavam diretamente na sua dinâmica, até então não abordados pelos "planejadores": a circulação, as residências, o subúrbio (ou a periferia) e as áreas destinadas ao comércio e à indústria. Em certa medida, Sitte (1992) foi o precursor do zoneamento como um instrumento de planejamento urbano, caracterizado pela aplicação de um sistema legislativo (geralmente na esfera municipal) que procurava regular o uso, a ocupação e o arrendamento da terra urbana por parte dos agentes de produção do espaço urbano, tais como construtoras, incorporadoras, proprietários de imóveis e o próprio Estado. As leis de zoneamento restringem o tipo de estrutura a ser construída em um dado local da cidade, com base em suas funções (as diferentes zonas: comerciais, residenciais, industriais ou mistas, em seu uso residencial ou comercial e, eventualmente, a indústria de baixa incomodidade).

\section{A cidade-jardim de Howard}

Em 1898, o inglês Ebenezer Howard escreveu um livro intitulado Tomorrow: a peaceful path to real reform, que foi reeditado, em 1902, com o título Garden cities of tomorrow. Howard (1996) sugeria a aquisição de uma gleba de 6.000 acres, em distrito agrícola, para ser conservada como propriedade única. Uma pequena parcela da área seria destinada a construções, enquanto o restante constituiria um cinturão permanente de parques e sítios. A cidade deveria possuir, em sua área, indústrias suficientes para proporcionar emprego aos seus habitantes, estabelecendo-se um limite para a população total. Essa sua proposta se concretiza em 1903 com a construção de Letchworth, a primeira cidade-jardim inglesa, a 32 milhas de Londres. As cidades-jardins inglesas exerceram grande influência sobre o planejamento das áreas residenciais suburbanas de alto padrão e as comunidades suburbanas dos Estados Unidos.

Por estar mais preocupada com a estrutura e a concepção de uma sociedade, a cidade-jardim de Howard ainda não é uma cidade propriamente dita, e sim uma estrutura que, como ele afirma, deverá ter sua forma estudada por arquitetos. Ela a projetava radiocêntrica, com a presença de um parque central, de avenidas e bulevares fartamente arborizados, edifícios públicos, mercado central, habitação unifamiliar - sendo que as condições higiênicas deveriam ser controladas pela municipalidade -, com tipologia arquitetônica variada (algumas casas seriam providas de jardins comuns e cozinhas cooperativas) e localização próxima ao local de trabalho dos moradores. 
A proposta de cidade-jardim de Howard apontava, ainda, três aspectos importantes: a questão fundiária, o papel das ferrovias e o desenho da cidade. É uma resposta à teoria de mercado e à da renda da terra, formuladas por economistas como von Thünen, ${ }^{3}$ neoclássico, e Ricardo, ${ }^{4}$ ligado à economia política. Em Ricardo (1982) identificamos que a renda fundiária era interpretada como uma manifestação particular da riqueza social. As classes sociais não eram vistas pelo acúmulo de riqueza, e sim por relações econômicas. Para ele, os latifundiários não produzem, e sim recebem parte do lucro em razão do direito à propriedade. A riqueza produzida no campo, portanto, não era obtida pelos trabalhadores, e sim pelos proprietários da terra.

Von Thünen identifica a riqueza como algo escasso. Nesse sentido, sua teoria da renda da terra tem por objetivo explicar a melhor forma de utilizar essa escassez. Para ele, o proprietário é um ser passivo e o mercado seria o melhor locador do uso do solo. A renda seria a expressão da concorrência espacial.

Na realidade, Howard (1996) era abertamente contra a organização social/produtiva capitalista. É razoável pensar, dessa forma, que a sua cidade-jardim venha a atacar exatamente essas formas de apropriação da renda da terra, do acúmulo de riqueza, pois, ao propor que a terra fosse um bem comum e que os lucros advindos de sua valorização (seja pela transformação do solo agrário em urbano, seja pela infraestrutura da cidade ou, ainda, pela produção agrária) sejam revertidos para a própria sociedade (seus reais proprietários), ele está, por um lado, contrapondo-se à lei do mercado e, por outro, negando o acúmulo do capital por apenas uma classe social.

Outro aspecto a ser destacado é o papel estruturador do espaço desempenhado pelas ferrovias nas cidades jardins. Para Lins (1998, p. 112), na cidade-jardim de Howard,

o limite externo que define o plano de transição entre a cidade e o campo é caracterizado pelo anel ferroviário. [...] a ferrovia, nesse caso, é definidora do espaço urbano, como se a área por ela ocupada formasse um anel divisório, quase como uma muralha. Junto à faixa de domínio da estrada de ferro estão dispostas as fábricas e os depósitos, reforçando a divisão espacial cidade-campo. [...] a relação da cidade-jardim com seu território é estabelecida pela via férrea. Assim também é tratada a ligação dos diversos núcleos ur- banos e, o que seria a capital, numa rede de cidades-jardins $[\ldots]$.

Lins (1998) aponta a ferrovia como elemento estruturador, capaz de dar unidade ao espaço, isto é, ligar áreas distintas, possibilitar a circulação de pessoas e mercadorias, além de ser um meio de transporte coletivo.

Por fim, quanto ao aspecto formal, seu desenho propriamente dito, Howard (1996), apresenta os diagramas como úteis para acompanhar a descrição da cidade em si. Entretanto seu desenho não é uma forma fechada, podendo ser amplamente modificado. A maior preocupação dele era com o conceito de cidade e não com a forma, podendo esta adquirir outra configuração, segundo seu projetista. Concluímos que, para ele, a concepção de sociedade é mais forte do que o desenho da cidade.

Em uma nota de rodapé de seu livro, Howard (1996, p. 135) relata sobre o desenho das cidades, fazendo alusão ao crescimento das cidades americanas.

É comum pensar que as cidades dos Estados Unidos são planejadas. Isso somente é verdadeiro no sentido mais inadequado. As cidades americanas certamente não constituem intrincados labirintos de ruas cujas linhas parecem ter sido traçadas por vacas [...]. Algumas ruas são traçadas, e à proporção que a cidade cresce, vão sendo estendidas e repetidas com uma monotonia raramente interrompida. Washington é uma magnífica exceção a esse padrão de arruamento, mas mesmo essa cidade não está planejada com a finalidade de assegurar a sua população acesso fácil à natureza, pois seus parques não são centrais nem suas escolas e outros edifícios estão distribuídos de forma científica. ${ }^{5}$

O aspecto que mais chamava a atenção de Howard (1996) era a acessibilidade das pessoas à natureza e aos edifícios públicos e o zoneamento funcional, assim como a dimensão estética que o arruamento das cidades deveria possuir, evitando o geometrismo.

Howard (1996) preconizava um desenho de cidade radiocêntrica, limitada por ferrovias, com a presença de um cinturão verde, de parques e ruas arborizadas. O zoneamento funcional, com restrições sobre o uso do solo urbano, a altura das construções e sua ocupação na malha urbana da cidade, também era um importante aspecto na concepção das cidades-jardins. $\mathrm{O}$ desenho das ruas teria que ser sinuoso, evitando

\footnotetext{
3. Johann Heinrich von Thünen nasceu em Canarienhausen, hoje Wangerland, Baixa Saxônia, em 24 de junho de 1783 . Foi um economista alemão, muito conhecido pela sua teoria da localização ou de ubicação sobre a geografia rural-urbana (Schumpeter, 1982).

4. David Ricardo nasceu em Londres em 18 de abril de 1772 e morreu em Gatcombe Park em 11 de setembro de 1823 . É considerado um dos principais representantes da economia política clássica.

5. Na nota 22, Howard comenta o crescimento das cidades inglesas, operadas por proprietários que intervinham de forma pontual e especulatória na cidade, destacando a necessidade de planos gerais.
} 
o geometrismo, e deveriam existir unidades de vizinhança. ${ }^{6}$ A moradia operária sintetizava a ideia de construção de uma nova comunidade com envolvimento da sociedade local. A propriedade da terra era da comunidade e os lucros advindos da valorização das terras eram revertidos para sua infraestrutura.

Parte das ideias de Howard chegou ao Brasil, mais precisamente a São Paulo, por volta da década de 1910, por intermédio da Companhia City, empresa de capital estrangeiro de especulação imobiliária que construiu uma forte relação com a prefeitura paulistana. Em São Paulo não houve a construção de cidades-jardins, e sim de bairros-jardins. A região escolhida da cidade foi o quadrilátero sudoeste, que contou com projetos de Barry Parker (propondo ou construindo) para os bairros Pacaembu, Jardim América, entre outros. Entretanto, nesses empreendimentos aparecem apenas algumas ideias de Howard, tais como: o nome do bairro, no caso Jardim América, com conotação simbólica; a forte presença de jardins e de avenidas arborizadas e as condições sanitário-higiênicas.

Vejamos alguns exemplos das intervenções urbanísticas da Companhia City em São Paulo: a região do bairro do Butantã era pouco valorizada e foi escolhida pela companhia porque, com o ritmo de crescimento de São Paulo, a cidade se expandiria naquela direção. A Companhia. City, antevendo as possibilidades de ganhos imobiliários, investiu em melhorias que atrairiam os compradores, interessados no inédito conceito urbanístico que a empresa implementaria pela primeira vez na América do Sul, a cidade-jardim. Era a primeira vez que um bairro seria construído de acordo com um planejamento prévio e seguindo as normas urbanísticas definidas pelo americano Ebenezer Howard.

A Companhia City foi a responsável pela abertura da Avenida Anhangabaú, atual Nove de Julho, assim como de seu prolongamento até o Jardim América na década de 1930, proporcionando à cidade um marco urbanístico característico da proposta de cidade-jardim. A avenida é hoje uma das mais utilizadas vias de circulação da capital paulistana. A região só começou a se desenvolver no fim do século XIX, motivada principalmente pela criação do Instituto Butantã, em 1899. A área que deu origem ao bairro era de propriedade da família Vieira de Medeiros, que a vendeu para a Companhia City em 1915. Uma grande área, com mais de $2.300 \mathrm{~m}^{2}$, que começou a ser urbanizada pela companhia por volta de 1930, dando origem ao bairro do Butantã.
Em 1935, após estudos iniciados dois anos antes, a Companhia City começou a urbanizar cerca de $80 \mathrm{mil} \mathrm{m}^{2}$ de terrenos e concluiu suas obras no fim da década, após a retificação do rio Pinheiros. Assim como já havia feito em outros bairros, a Companhia City adotou os modelos urbanísticos da cidade de Howard. Mais tarde, a região acabou por se beneficiar com a construção do Jockey Clube e da Cidade Universitária. Os projetos de Barry Parker para os referidos bairros incorporaram noções da cidade-jardim, tais como avenidas arborizadas, jardins e condições sanitário-higiênicas, ruas sinuosas, evitando o geometrismo, formato radiocêntrico dos bairros e a presença de um parque central.

\section{A experiência francesa}

A partir de 1925, em Paris, sob o governo de Pincaré, foi criado o Comitê Superior de Organização da Região Parisiense. Posteriormente, em 1932, uma lei obrigava a preparação de um plano de urbanismo regional. Elaborado por Henri Prost ${ }^{7}$ e aprovado em 1939, jamais foi aplicado. Após a Segunda Guerra Mundial, recebendo uma influência direta das ideias de J. F. Gravier, expressas em seu livro Paris et le désert français, iniciou-se a implantação de uma política de descentralização industrial e de ordenação do território. Um decreto datado de 31 de dezembro de 1958 instituiu o Plano de Ordenação e Organização Geral da Região Parisiense (Padog) - em que foi determinado o perímetro além do qual a aglomeração não deveria expandir-se -, que foi aprovado por decreto em 1960.

Sua ineficiência, no entanto, era patente, pois no mesmo ano a metade das habitações autorizadas estava excepcionalmente fora do perímetro de urbanização. No ano de 1961, foi criado o distrito da região parisiense. M. Delouvier, delegado geral de Paris, encomendou um plano diretor de ordenação e de urbanismo da região de Paris, publicado em 1965. Esse documento traçou uma série de políticas, dentre elas, a criação de novas cidades francesas que contribuíssem para o desenvolvimento da região urbana ao redor da capital.

Harouel (1990) demonstra a impotência do poder público diante do gigantismo urbano que, entre outras características inconvenientes e inerentes à sua enormidade, apresenta alto nível de vida, o que, por

\footnotetext{
6. Unidade de Vizinhança é, segundo a formulação original do início do século 20, uma área residencial que dispõe de relativa autonomia com relação às necessidades quotidianas de consumo de bens e serviços urbanos (Barcellos, 2001).

7. Henri Prost foi cofundador da Sociedade Francesa dos Urbanistas em 1911, junto com os arquitetos Donat Alfred-Agache, Sr. Auburtin, A. Bernard, Hernard Eugene, Leon Jaussely, A. Parenty, o engenheiro Jean Claude Nicolas Forestier e o arquiteto e paisagista Eduardo Redont. Ver: Frei; Prost (2004).
} 
outro lado, não ocorre nas grandes cidades da maioria dos outros países em desenvolvimento. Nesses locais, o gigantismo se revela assustador, dada a sua faceta particularmente desumana, resultado do imenso crescimento demográfico. Nesses casos, o aumento populacional segue uma progressão geométrica, pois há o crescimento do número de nascimentos e a queda da taxa de mortalidade, de maneira contrária ao que se passou no ocidente, onde o crescimento demográfico precede o progresso econômico, em vez de acompanhá-lo. Assim, foi necessário, a posteriori, suscitar um processo de desenvolvimento destinado a possibilitar a sobrevivência do excedente populacional (Harouel, 1990).

Nos países em desenvolvimento, a explosão urbana segue de maneira acentuada a que ocorreu na Europa do século XIX. Caracas quintuplicou a sua população depois da Segunda Guerra Mundial. Lima, São Paulo e do México assistiram à sua população triplicar. Em Argel e Teerã, a população triplicou e quadriplicou, respectivamente, nas duas últimas décadas. No entanto, o exemplo mais gritante é o da cidade do Cairo, pois, concebida para 3 ou 4 milhões de habitantes, contava, no início da década de 1990, com aproximadamente dez milhões.

Harouel (1990) chama a atenção para o fato de as cidades dos países em desenvolvimento não conseguirem acolher as mudanças promovidas pelas massas humanas que afluíram para os seus espaços. Assim, são rodeadas de imensos subúrbios constituídos de favelas.

Em Lima, um terço da população vive em favelas. Mesmo Brasília possui suas favelas. Em algumas dessas cidades não existe nem mesmo eliminação de esgoto e coleta de lixo. Os detritos acumulam-se na periferia em verdadeiras colinas e das quais vive um povo miserável de mendigos e dos quais retiram sua subsistência. (Harouel, 1990, p. 141-142)

Apesar de sua miséria dramática, as cidades dos países em desenvolvimento são locais de esperança, onde talvez se tenha a chance de obter um emprego produtivo e, portanto, um salário.

Contudo, voltando à experiência francesa de antecipação e ordenação da ocupação do solo urbano, que se inicia, concretamente, a partir da metade do século XIX e principalmente do início do século XX, consolida-se um sistema de licença para construir.

$O$ decreto de 26 de março de 1853 criou em $\mathrm{Pa}-$ ris uma licença para construir "no interesse da segurança e da salubridade". A lei de 15 de fevereiro de 1902 impõe de maneira genérica uma autorização para construir destinada a assegurar a proteção da saúde pública. Mais tarde, em 13 de julho de 1911, interpõe-se uma lei relativa às perspectivas monumentais e aos sítios que institui um sistema de autorização prévia por motivos estéticos. Nos anos 1919 e 1924, seguem leis relativas aos planos de ordenação que fazem da licença de construir a sanção do plano das cidades em questão. A última alteração na licença de construir ocorre em 1943, que, na verdade, unificou todas as licenças anteriores. Posteriormente, o sistema de licença de construir se mantém, sendo reforçado somente pela lei de 31 de dezembro de 1976, que também institui uma licença para demolir.

No entanto, se formos focalizar a planificação urbana, ela somente apareceu com as leis de 14 de março de 1919 e 19 de julho de 1924, que determinavam que todas as cidades com mais de dez mil habitantes, assim como uma série de outras comunas, deveriam ter, no prazo de três anos, "um plano de ordenação, de embelezamento e de expansão" (Harouel, 1990, p. 44). Mesmo assim, essas determinações não foram respeitadas.

Uma nova etapa inicia-se com a reforma de 1958-1959, que institui a distinção entre plano diretor de urbanismo - para Harouel (1990), a verdadeira carta do desenvolvimento urbano dotada de um caráter mais permanente - e os planos parciais, que podiam ser revisados mais facilmente. No entanto, esse sistema foi modificado pela lei de diretrizes fundiárias de 1967, que criou os planos diretores de planejamento e de urbanismo (SDAU) e os planos de ocupação do solo (POS), que representavam uma planificação a curto termo e organizavam uma divisão do espaço em uma série de zonas, nas quais as condições de construção encontravam-se regulamentadas com precisão. Esse sistema determinava que, para zona, o POS fixava um coeficiente de ocupação (COS) que, por sua vez, determinava a densidade máxima de construção sobre um dado terreno. O COS podia ser elevado em zona urbana (2 ou 2,5), mas baixo em zona rural, e raramente nulo, o que seria nocivo ao meio ambiente.

A lei fundiária de 31 de dezembro de 1976 tentava resguardar as regiões rurais não amparadas por um COS contra a urbanização anárquica criando zonas protegidas do meio ambiente (ZEP). Em 1958, foram instituídas as zonas urbanizáveis prioritárias (ZUP). Elas objetivavam concentrar esforços de urbanização em certos perímetros determinados fora dos quais a licença de construir poderia ser recusada. Finalmente, a lei fundiária de 1967 substitui o sistema das ZUP pelo das ZAC (zonas de planejamento coordenadas). Elas determinavam um quadro jurídico que poderia servir de suporte às operações de urbanismo de qualquer natureza. 


\section{Conclusões}

As preocupações que nortearam a formulação dos instrumentos franceses de ordenação e regulamentação da ocupação do solo urbano serviram de base para o "pensar" urbanístico brasileiro. A experiência francesa é a mais significativa na constituição do que denominamos urbanismo brasileiro. Vejamos como essas influências e seus desdobramentos se deram a partir de dois autores: Haussmann e Agache.

As intervenções em aglomerados existentes, com a finalidade de saneá-los e transformá-los segundo as necessidades de seu tempo, foram as que mais se notabilizaram nas grandes intervenções empreendidas por Haussmann em Paris.

Segundo Toledo (1996, p. 110), o Barão de Haussmann

promoveu uma operação extensiva de reorganização, homogeneização e saneamento da cidade, que implicaram excessivos trabalhos de demolição. Esse fato lhe rendeu, por várias vezes, críticas, já que grande parte dos edifícios e do tecido urbano medieval da cidade foram sacrificados. As novas construções utilizaram, em sua maioria, um repertório eclético sem muita originalidade, mas discreto e regular. Esse fator, somado ao apego à linha reta para abertura de grandes avenidas, foi interpretado como meio de sanear a cidade e, também, como estratégia para facilitar a ação armada, em caso de revoltas. ${ }^{8}$

[...] As decisões baseavam-se num pormenorizado levantamento e estudo da situação existente em toda a cidade e na consideração do fator 'tempo', analisando, dessa forma, a história do local e, igualmente, dados estatísticos para sua projeção futura. Seus objetivos eram muito mais abrangentes do que os de seus contemporâneos, uma vez que ele encarava o espaço urbano como um organismo que, para operar com funcionalidade, não poderia ser apenas a justaposição de suas partes. Sua forma de atuar estava alicerçada, principalmente, no estabelecimento de um sistema de circulação e de aeração, onde a questão do fluxo de tráfego era prioritária.

No Brasil, a mais conhecida e estudada influência do urbanismo francês foi a sofrida pela cidade do Rio de Janeiro. A primeira intervenção mais ampla ocorreu nessa cidade entre 1902 e 1906, durante a gestão de Pereira Passos. ${ }^{9}$ Segundo Stuckenbruck (1996), Passos teve um papel importante, por haver incorporado a concepção de reforma urbana ao po- der estatal e sua consequente objetivação em obras públicas.

Para Stuckenbruck (1996, p. 107):

Em Passos, o que se faz é abrir ruas, praças, alargar avenidas, construir um rígido código de posturas, regulamentando o uso do espaço urbano - mas não há um projeto para a cidade como um todo, não há técnicos especializados na cidade, não há um campo definido de atuação para o futuro profissional urbanista -, não há urbanismo! O que há são intervenções pontuais e localizadas na malha urbana, orientadas pelos princípios do higienismo e da ciência positiva.

Sevcenko (1996, p. 106) diz sobre esse período:

A imagem de progresso se transforma na obsessão coletiva da nova burguesia; quatro princípios fundamentais regeram o transcurso dessa metamorfose: a condenação dos hábitos e costumes ligados pela memória da sociedade tradicional; a negação de todo e qualquer elemento da cultura popular que pudesse macular a imagem civilizada da sociedade dominante; uma política rigorosa de expulsão dos grupos populares da área central da cidade, que será praticamente isolada para o desfrute exclusivo das camadas aburguesadas; e um cosmopolismo agressivo, profundamente identificado com a vida parisiense.

Completando com Pechman (1994, p. 105):

Entre nós, as ideias urbanísticas tiveram muito mais um caráter de resolução de problemas técnicos e intervenção da cidade do que o de uma política de reforma urbana baseada no pressuposto da necessidade de planejamento da cidade que enquadrasse seus problemas sociais derivados de uma má urbanização. Aqui a experiência urbanística se esgota na regeneração do corpo urbano e na hierarquização do corpo social, sem necessitar negociar melhorias nas condições de vida dos grupos, nas suas práticas cotidianas, nas normas sanitárias.

É no bojo desse debate que ocorre o episódio da Revolta da Vacina no Rio de Janeiro, estimulada, principalmente, pela execução de uma proposta urbanística que se impunha à cidade do Rio de Janeiro, sem levar em conta o corpo social, sem negociar melhorias nas condições de vida dos grupos, enfim, de forma arrogante.

Na década de 1920, o discurso se altera. A cidade passa a ser objeto de intervenções que abarcavam

8. Haussmann pensava em alternativas que pudessem facilitar o combate a levantes como os que ocorreram no ano de 1871 com a Comuna de Paris.

9. Para Andrade (1992), a intervenção de Pereira Passos no Rio de Janeiro visava a criar uma imagem de cidade europeia em pleno trópico. No entanto, teve caráter pontual e fragmentário, sem pretender dar uma resposta ao problema do crescimento da cidade a médio ou longo prazo. 
sua totalidade e, para isso, intensifica-se a necessidade de um corpo técnico especializado que contasse com o respaldo do status científico. Para Stuckenbruck (1996, p. 111), "o que caracteriza esse momento é uma mudança de conteúdo no discurso sobre o urbano, marcada pelo surgimento de novos profissionais especializados e pela concepção global da cidade, utilizando-se da metáfora do organismo, emprestada do saber médico".

O debate sobre os destinos das cidades ganhava o interesse dos mais variados setores da sociedade, desde engenheiros e técnicos da prefeitura até médicos sanitaristas, passando pela opinião pública. O poder público, nesse contexto, produz clara política de urbanização da cidade, e como não poderia deixar de ser, repleta de interesses elitistas. Na segunda metade da década de 1920, foi elaborado um plano de urbanização para a cidade do Rio de Janeiro, que veio a ser conhecido como Plano Agache. Consistia em grandes avenidas arborizadas e áreas com jardins para o centro. Essas mudanças pelas quais as cidades passavam abrangiam questões de saneamento básico, água, esgotos e drenagem, escoamento do lixo e das inundações e circulação como uma das principais funções da cidade. Propunha, ainda, a implantação de um sistema metroviário e a criação de áreas habitacionais com deslocamento da população de baixa renda para os subúrbios, e os de alta para os bairros-jardins na Zona Sul. Para Abreu (1992), o Plano Agache constitui o exemplo mais importante da tentativa das classes dominantes da República Velha de controlar o desenvolvimento da forma urbana carioca.

As análises realizadas apontam que se efetiva uma corrente do pensamento urbanista no estado de São Paulo com nítidas influências das concepções do sanitarismo, da visão historicista de Camille Sitte (1992), da cidade-jardim de Howard (1996) e das concepções francesa e americana. As concepções brevemente apresentadas neste artigo efetivamente contribuíram para a formulação do que classificamos de corrente do pensamento urbanístico paulista. Salientamos, entretanto, que as três primeiras concepções - a sanitarista, a historicista de Camille Sitte (1992) e a da cidade-jardim de Howard (1996) - compõem um quadro de intervenções urbanas na cidade de São Paulo e, visivelmente, em algumas cidades do interior paulista, anteriores à solidificação de uma concepção totalizante de cidade. Em outras palavras, tais visões serviram de inspiração para intervenções pontuais nessas cidades, contribuindo ainda mais para a solidificação de um processo de exclusão urbana.

A construção de propostas urbanas que se cristalizaram em planos, então voltados para o todo, está vinculada à formação de aparato conceitual que desse conta, a partir do ano de 1954, quando São Paulo assume a condição de primeira metrópole brasileira, dos atributos da cidade, cuja abordagem tornou-se praticamente inacessível ao urbanismo paulistano. Naquele momento, São Paulo desafiava o urbanismo e os seus mais experientes profissionais. Portanto, foi a partir da década de 1950 que se construiu um ponto de inflexão na trajetória das relações entre a metrópole e o urbanismo que já assumia sua nova versão: a de planejamento urbano.

A constatação de Tafuri (1985), ao analisar as relações entre metrópoles europeias e o urbanismo da segunda e da terceira décadas do século XX, mostra que tanto a metrópole quanto o urbanismo viviam condições de convívio inviável. Entendemos que São Paulo, guardadas as devidas proporções, também vivia essa relação conflituosa e contraditória entre metrópole e urbanismo. O centro da argumentação de Tafuri (1980) é que a metrópole do desenvolvimento não aceita "o equilíbrio no seu seio". Na cidade de São Paulo, no período de 1950 a 1960 - metrópole do desenvolvimento -, o urbanismo moderno, tal como o qualificou Tafuri (1980), não encontrava seu lugar na desenfreada caminhada da metrópole do progresso.

Ao percorrermos e analisarmos as diferentes propostas de intervenção na metrópole e a ideia de cidade contida em cada uma delas se pretendeu demonstrar os limites conceituais que cada modelo de reflexão e intervenção apresenta. $\mathrm{O}$ embate conceitual entre as ideias defendidas por Luiz Anhaia Mello e Francisco Prestes Maia - ambos ex-prefeitos de São Paulo e profissionais envolvidos com essas duas dimensões, a conceituação e a prática urbanística - representou um ponto notável do pensamento urbano em São Paulo. 


\section{Referências}

ANDRADE, Carlos Roberto Medeiros de. A Peste e o Plano. O urbanismo sanitarista do engenheiro Saturnino de Brito. Dissertação (Mestrado em Estruturas Ambientais Urbanas). Faculdade de Arquitetura e Urbanismo, Universidade de São Paulo, São Paulo, 1992.

BARCELLOS, Vicente. Unidade de vizinhança: notas sobre sua origem, desenvolvimento e Introdução no Brasil. Universidade de Brasília, Faculdade de Arquitetura e Urbanismo, Brasília, 2001. Cadernos eletrônicos. Disponível em: <http://www.unb.br/fau/pos_graduacao/ cadernos_eletronicos/unidade/unidade.htm $>$. Acesso em: 05 de fevereiro de 2010.

CAMPOS, Cristina de. São Paulo pela lente da hygiene: as propostas de Geraldo de Paula Souza para a cidade (19251945). São Carlos, SP: RiMa Editora, 2002.

COSTA, Luiz Augusto Maia. O ideário urbano paulista na virada do século. O engenheiro Theodoro Sampaio e as questões territoriais e urbanas modernas (1886-1903). São Carlos, SP: RiMa/Fapesp, 2003.

Planejamento antes do planejamento. Cidade e território em São Paulo, 1886-1903. In: GITAHY, M. L. C. Desenhando a cidade do século XX. Estudos de história e fundamentos sociais da arquitetura e do urbanismo em São Paulo, 1870-1970. São Carlos, SP: RiMa/Fapesp, 2005. p. 55-60

DAMASCENO, Angela Nunes Rio de Janeiro: a cidade que os médicos pensaram e os engenheiros produziram. In: Seminário de História da Cidade e do Urbanismo, 4, Rio de Janeiro, 1996. Anais... Rio de Janeiro: UFRJ/ Prourb.

FERNANDES, Bernardo Mançano. Questão Agrária, pesquisa e MST. São Paulo: Cortez Editora, 1995.

FREY, Jean-Pierre. Henri Prost (1874-1959), um planeador de rotas distintas. Urbanismo, n. 336, p. 56-60, maio/jun. 2004.

HAROUEL, Jean-Louis. História do urbanismo. Campinas, SP: Papirus, 1990.
HOWARD, (Sir) Ebenezer. Cidades-jardins de amanhã. Trad. Marco Aurélio Lagonegro. São Paulo: Hucitec, 1996.

LINS, Antônio José Pedral Sampaio. A ferrovia e três utopias urbanas, ou como os pioneiros viam o trem: uma análise comparativa entre "Cidades Jardins", "Cidades Linear" e "Cidade Industrial". In: Seminário de História da Cidade e do Urbanismo, 5, 1998, São Paulo. Anais... São Paulo: PUC-Campinas, 1998. 1 CD-ROM.

PECHMAN, Robert Moses. Olhares sobre a cidade. Rio de Janeiro: Editora da UFRJ, 1994.

RICARDO, David. Princípios de economia política e tributação. Introdução de Piero Sraffa. Apresentação de Paul Singer. Trad. de Paulo Henrique Ribeiro Sandroni. São Paulo: Abril Cultural, 1982. (Os Economistas).

SCHUMPETER, Joseph Alois. Historia del análisis económico. 2. ed. Barcelona: Editorial Ariel, 1982.

SEVCENKO, Nicolau. Orfeu extático na metrópole. São Paulo: Sociedade e cultura nos frementes anos 20. $1^{\text {a }}$ reimp. São Paulo: Companhia das Letras, 1996.

SITTE, Camillo. A construção das cidades segundo seus princípios artísticos. São Paulo: Ática, 1992.

STUCKENBRUCK, Denise Cabral. O Rio de Janeiro em questão: o plano agache e o ideário dos anos 20. Rio de Janeiro: Editora da UFRJ, 1996.

SZMENCSÁNY, Maria Irene Queiroz Ferreira. Produção, apropriação e organização do espaço na economia cafeeira: contrastes entre o Vale do Paraíba e o Oeste paulista (1880-1930). Sinopses. São Paulo, n. 5, p. XX-XX, 1993.

TAFURI, Manfredo. Viena Rossa. La politica residenziale nella Vienna socialista, 1919-1933. Milano: Electra, 1980. Projecto e utopia: arquitectura e desenvolvimento do capitalismo. Trad. C. Jardim e E. Nogueira. Lisboa: Presença, 1985.

TOLEDO, Benedito Lima de. Prestes Maia e as origens do urbanismo moderno em São Paulo. São Paulo: Empresa das Artes, 1996. 


\title{
The influence of European concepts in the development of Paulista urban thought
}

\begin{abstract}
This article aims to present a list of the main influences experimented by architects and urbanists to formulate an urban thought of Sao Paulo City. This way, it will be discussed the main issues raised between the first decades of the XX Century until the 1950s, trying to foresee how the engineers and architects worked to incorporate the urbanistic proposals from Europe and the United States. On the first three sections of this article, it will be presented the concepts that effectively impacted the paulista urban thought of the first half of the XX Century: Sanitarism, the pendulum design: between the Mesologic Theory and the Microbian Theory; Camillo Sitte's historicist formulation; Howard Garden Town and the French experience. Our analysis was formulated by having as a reference a broad and systematic literature, documents stored at Arquivo Histórico Municipal de Araraquara (SP), visits to Faculdade de Arquitetura e Urbanismo da USP Library and to Faculdade de Ciências e Letras da Unesp, Araraquara. The analysis shows that two urbanistic planner streams that happened in São Paulo State were clearly influenced by the conceptions that led the urbanistic debates in the first half of the XX Century. So, these conceptions compose a painting of the urban interventions in São Paulo City.
\end{abstract}

Key-words: urban thought, urban planning, democracy, participation, public policies.

\section{Influencia de conceptos europeos en la formulación del pensamiento urbano paulista}

\section{Resumen}

En este artículo se propone una lista de las principales influencias experimentadas por los arquitectos y urbanistas para formular un pensamiento urbano de São Paulo. Por lo tanto, se discuten las principales cuestiones planteadas en el período transcurrido desde las primeras décadas del siglo XX hasta la década de 1950, tratando de anticipar cómo trabajaban los ingenieros y arquitectos para incorporar la propuesta urbana de Estados Unidos y Europa. Por lo tanto, se presenta, en los tres primeros apartados de este artículo, los conceptos que realmente impactaron a la ciudad de São Paulo de la primera mitad del siglo XX: Sanitarismo, concepción pendular entre la Teoría Microbiana y la Teoría Mesológica; formulación historicista de Camillo Sitte; Ciudad - Howard Garden y la experiencia francesa. Nuestros análisis se obtuvieron de la literatura extensa y sistemática, documentos conservados en el Archivo Histórico Municipal (Intermedio) en Araraquara, las visitas a la colección de la biblioteca de la Facultad de Arquitectura y Urbanismo de la USP y el Colegio de Letras y Ciencias de la Unesp de Araraquara, estado de São Paulo. Los análisis de los estudios sistemáticos indican que dos corrientes urbanísticas se han puesto en marcha en el estado de São Paulo, con claras influencias de concepciones principales y planificadores de los debates en la primera mitad del siglo XX. Sin embargo, estos conceptos constituyen un marco para las intervenciones urbanas en la ciudad de São Paulo y, visiblemente, en algunas ciudades del interior para la solidificación de una propuesta previa y intervención de la ciudad total llamada, a partir de entonces, el Plan Maestro.

Palabras-clave: pensamiento urbano, la planificación urbana, la democracía, la participación, las políticas públicas.

Data de recebimento do artigo: 14/02/2012

Data de aprovação do artigo: 30/07/2012 